\title{
(6) OPEN ACCESS \\ Filgotinib (GLPG0634/GS-6034), an oral selective JAK1 inhibitor, is effective as monotherapy in patients with active rheumatoid arthritis: results from a randomised, dose-finding study (DARWIN 2)
}

\author{
A Kavanaugh, ${ }^{1}$ J Kremer, ${ }^{2}$ L Ponce, ${ }^{3}$ R Cseuz, ${ }^{4}$ O V Reshetko, ${ }^{5}$ M Stanislavchuk, ${ }^{6}$ \\ $\mathrm{M}$ Greenwald, ${ }^{7} \mathrm{~A}$ Van der $\mathrm{Aa}^{8}{ }^{8} \mathrm{~F}$ Vanhoutte, ${ }^{8} \mathrm{C}$ Tasset, $^{8} \mathrm{P}$ Harrison $^{8}$
}

Handling editor Tore K Kvien

- Additional material is published online only. To view please visit the journal online (http://dx.doi.org/10.1136/ annrheumdis-2016-210105)

For numbered affiliations see end of article.

Correspondence to Professor A Kavanaugh, Center for Innovative Therapy, Division of Rheumatology, Allergy \& Immunology, School of Medicine, University of California San Diego, 9500 Gilman Drive \#0656, La Jolla, CA 92093, USA; akavanaugh@ ucsd.edu

Received 22 June 2016 Revised 1 November 2016 Accepted 5 November 2016 Published Online First 19 December 2016

\section{Linked}

- http://dx.doi.org/10.1136/ annrheumdis-2016-210104

\section{CrossMark}

To cite: Kavanaugh $\mathrm{A}$, Kremer J, Ponce L, et al. Ann Rheum Dis 2017:76:1009-1019.

\section{ABSTRACT}

Objectives To evaluate the efficacy and safety of different doses of filgotinib, an oral Janus kinase 1 inhibitor, as monotherapy in patients with active rheumatoid arthritis (RA) and previous inadequate response to methotrexate (MTX).

Methods In this 24-week phase Ilb study, patients with moderately to severely active RA were randomised $(1: 1: 1: 1)$ to receive 50,100 or $200 \mathrm{mg}$ filgotinib once daily, or placebo, after $a \geq 4$-week washout from MTX. The primary end point was the percentage of patients achieving an American College of Rheumatology (ACR) 20 response at week 12 .

Results Overall, 283 patients were randomised and treated. At week 12, significantly more patients receiving filgotinib at any dose achieved ACR20 responses versus placebo ( $\geq 65 \%$ vs $29 \%, p<0.001)$. For other key end points at week 12 (ACR50, ACR70, ACR-N, Disease Activity Score based on 28 joints and $C$ reactive protein, Clinical Disease Activity Index, Simplified Disease Activity Index and Health Assessment Questionnaire-Disability Index) significant differences from baseline in favour of filgotinib 100 and $200 \mathrm{mg}$ versus placebo were seen; responses were maintained or improved through week 24. Rapid onset of action was observed for most efficacy end points. Dose-dependent increases in haemoglobin were observed. The percentage of patients with treatment-emergent adverse events (TEAE) was similar in the placebo and filgotinib groups ( 40\%). Eight patients on filgotinib and one on placebo had a serious TEAE, and four patients, all of whom received filgotinib, experienced a serious infection. No tuberculosis or opportunistic infections were reported.

Conclusions Over 24 weeks, filgotinib as monotherapy was efficacious in treating the signs and symptoms of active RA, with a rapid onset of action. Filgotinib was generally well tolerated.

Trial registration number NCT01894516.

\section{INTRODUCTION}

The disease-modifying antirheumatic drug (DMARD) methotrexate (MTX) is a cornerstone of rheumatoid arthritis (RA) treatment, improving outcomes in many patients. ${ }^{1}$ However, even with optimal dosing only around $50 \%$ of patients respond adequately to MTX. ${ }^{2} 3$

Janus kinase (JAK) inhibitors are low molecular weight, orally available products that can impact intracellular molecules involved in the signalling of various cytokines, growth factors and hormones, such as pro-inflammatory cytokine interleukin- $6 .{ }^{4}$ The JAK1/JAK3, JAK2 inhibitor tofacitinib has been approved by the Food and Drug Administration for second-line use after MTX in patients with moderately to severely active RA. ${ }^{5}$ A number of other JAK inhibitors are currently in development for the management of RA, with differing in vitro specificities towards the various members of the JAK family. ${ }^{6}$

Filgotinib (GLPG0634/GS-6034) is a potent and selective inhibitor of JAK $1,{ }^{7}$ which is currently under investigation for the treatment of RA and inflammatory bowel disease. ${ }^{7-10}$ The efficacy and safety of filgotinib in patients with RA has previously been investigated in two short-term phase IIa studies, as add-on treatment to MTX, which suggested that filgotinib has the potential to be effective when administered as a once-daily dosing regimen. ${ }^{11-13}$ In pharmacokinetic-pharmacodynamic studies, filgotinib was shown to have a terminal half-life $\left(t_{1 / 2}\right)$ of 5-11 hours with an active metabolite that has a $t_{1 / 2}$ of 21-27 hours; both moieties contribute to the pharmacodynamic effects and together provide a relatively long duration of JAK1 inhibition, ${ }^{10}$ supporting further investigation of a once-daily dosing regimen.

The DARWIN 2 study reported here was conducted to evaluate the efficacy and safety of varying once-daily doses of filgotinib, administered as monotherapy in patients with moderately to severely active RA, who had an inadequate response to previous MTX treatment.

\section{METHODS}

\section{Study design and treatments}

This was a 24-week, multicentre, randomised, double-blind, phase IIb, dose-finding study of orally administered filgotinib as monotherapy (ClinicalTrials.gov identifier: NCT01894516). The study was conducted at 59 centres in 18 countries (Argentina, Austria, Bulgaria, Chile, Columbia, Germany, Guatemala, Hungary, Latvia, Mexico, Moldova, New Zealand, Poland, Romania, Russian Federation, Spain, Ukraine and the USA) across four predefined geographic regions. Eligible patients were randomly assigned to treatment using a computerised interactive voice and web response system 
(IXRS) (S-Clinica, 6, Chaussée de Boondael, 1050 Brussels, Belgium), to receive placebo or 1 of 3 filgotinib regimens (50, 100 or $200 \mathrm{mg}$ ), each as two capsules administered once daily in the morning), in a 1:1:1:1 ratio, stratified by region and previous use of biological DMARDs (bDMARDs). At each study visit, numbered kits containing medication were dispensed via the IXRS system. Patients, investigators, study coordinators, the sponsor and study team were blinded to treatment assignment. At week 12, all patients in the placebo group, and patients in the filgotinib $50 \mathrm{mg}$ group who had not achieved at least a $20 \%$ improvement in swollen joint count based on 66 joints (SJC66) and tender joint count based on 68 joints (TJC68), were reassigned to receive filgotinib $100 \mathrm{mg}$ and continued on this dose until week 24.

The study was conducted in accordance with the ethical principles based on the Declaration of Helsinki, Good Clinical Practice, International Council for Harmonisation guidelines and all applicable national and local laws and regulatory requirements.

\section{Patients}

Enrolled patients were $\geq 18$ years of age with a diagnosis of RA for $\geq 6$ months prior to screening and met the 2010 American College of Rheumatology (ACR)/European League Against Rheumatism (EULAR) criteria for RA and ACR functional class I-III, had $\geq 6 /$ SJC66 and $\geq 8 /$ TJC68, a screening serum $C$ reactive protein $(\mathrm{CRP}) \geq 0.7 \times$ upper limit of laboratory normal range (ULN) (changed in May 2014 from $1.5 \times$ ULN to facilitate recruitment), had shown an inadequate response to MTX (in the opinion of the treating physician) and agreed to be washed out from MTX for $\geq 4$ weeks before or during screening. Patients receiving oral glucocorticoids ( $\leq 10 \mathrm{mg} / \mathrm{day})$ or nonsteroidal anti-inflammatory drugs were on a stable dose for $\geq 4$ and $\geq 2$ weeks, respectively, prior to baseline. Enrolled patients were also required to be using a medically acceptable means of contraception. Details of laboratory-defined inclusion criteria are listed in the online supplementary materials.

Patients were excluded if they were receiving current therapy with any DMARD (with the exception of antimalarials), or had previous RA treatment with a bDMARD. The only exception to this was if the biological agent had been received in a single clinical study more than 6 months prior to enrolment and if the drug had been effective. Patients were also excluded if they had ever used any kind of JAK inhibitor, had previously used a cytotoxic agent other than MTX or had received intra-articular or parenteral corticosteroid injection within 4 weeks of screening. Patients who were pregnant were excluded, as were patients who were immunocompromised and, in the opinion of the investigator, participation in the study would pose an unacceptable risk. Further details of the exclusion criteria, including a list of infections that precluded enrolment in the study, are listed in the online supplementary materials. All patients provided written informed consent prior to study participation.

\section{Outcomes and assessments}

Efficacy and disease activity assessments were performed at screening (joint counts and Patient's Global Assessment of Disease Activity), baseline and at weeks 1, 2, 4, 8, 12, 16, 20 and 24. The primary efficacy end point was the percentage of patients achieving an ACR20 response at week 12. Key secondary end points were the percentages of patients achieving ACR20, ACR50, ACR70 and ACR-N responses, Disease Activity Score based on 28 joints and CRP value (DAS28 (CRP)), including remission and Low Disease Activity (LDA)/remission), EULAR response, ACR/EULAR remission, Clinical Disease
Activity Index (CDAI) and Simplified Disease Activity Index (SDAI) compared with placebo at every visit from baseline to week 24. Health-related quality of life (HRQoL) was assessed with the Health Assessment Questionnaire-Disability Index up to week 24.

Safety variables included adverse events (AEs) throughout the study period; vital signs (at each visit); physical examinations (at screening, baseline, week 12 and week 24) and 12-lead ECG (at screening, week 12 and week 24). Haematology and clinical chemistry laboratory assessments were performed at each visit. The National Institutes of Health Common Terminology Criteria for Adverse Events (CTCAE) V.3.0 was used to describe laboratory changes during the study.

\section{Sample sizes and statistical analyses}

All randomised patients who received at least one dose of study drug were included in the intent-to-treat (ITT) and safety populations. All patients in the placebo group and patients who were considered non-responders on filgotinib $50 \mathrm{mg}$ once daily and were switched to $100 \mathrm{mg}$ once daily at week 12, were handled as discontinuations and data were imputed from week 12 onwards. Efficacy data were analysed using non-responder imputation (NRI) for the ITT population and confirmed using last observation carried forward (LOCF) and observed case imputations in the ITT population, and NRI and LOCF imputations in the per-protocol population.

The primary analysis was conducted using a logistic regression model including treatment, region and previous use of bDMARDs as covariates. Continuous parameters were analysed using analysis of covariance. Time-to-first response (ACR20/50/ 70) was analysed using Kaplan-Meier survival techniques, with treatment groups compared with placebo using a Cox proportional hazard regression model. Treatment versus placebo comparisons were carried out for each dose group using Hommel's closed-testing correction procedure to adjust for multiplicity.

For the safety analysis, two periods were analysed: the period up to week 12 including the four original groups, and the full 24-week period including five treatment groups (two switched groups and three continued groups).

A sample size of 280 patients (70 patients in each arm) was estimated to provide $90 \%$ power to detect a minimum $28 \%$ $30 \%$ treatment effect versus placebo, assuming a 15\%-40\% placebo ACR20 response at week 12.

\section{RESULTS}

The study was initiated in October 2013 and completed in May 2015. Of the 625 patients screened, 287 were randomised to receive treatment, and 283 received at least one dose of study drug and were included in the ITT and safety populations (figure 1). At week 12, all patients in the placebo group $(n=65)$ and 15 non-responding patients in the filgotinib $50 \mathrm{mg}$ group were re-allocated to filgotinib $100 \mathrm{mg}$. The overall treatment discontinuation rate was low $(n=26,9.2 \%)$ and there were no significant differences in discontinuation rate between filgotinib and placebo groups, with no dose-response relationship apparent with respect to discontinuation rates. Demographic and baseline disease characteristics were well balanced between the different treatment groups (table 1), apart from a numerically higher mean CRP in the placebo group (not statistically significant, $\mathrm{p}=0.0865)$. Overall, 167/283 (59\%) patients received concomitant systemic corticosteroid treatment and 12/283 (4.2\%) patients received concomitant antimalarial treatment during the study. 


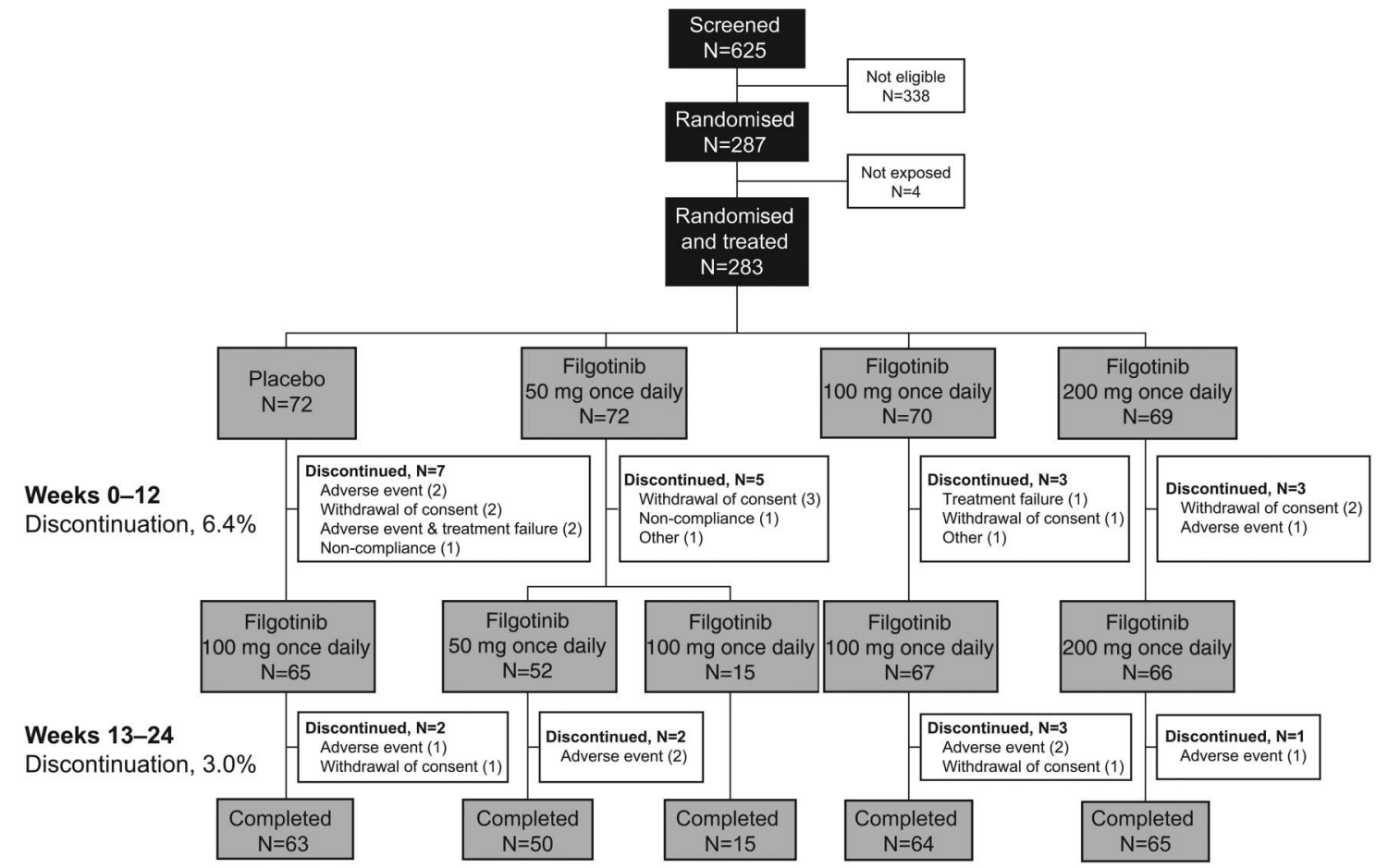

Figure 1 Patient disposition. The study was conducted at 59 centres in 18 countries (Argentina, Austria, Bulgaria, Chile, Columbia, Germany, Guatemala, Hungary, Latvia, Mexico, Moldova, New Zealand, Poland, Romania, Russian Federation, Spain, Ukraine and the USA).

\section{Efficacy}

Primary efficacy analysis

The primary end point of the study was met: at week 12, a statistically significantly higher proportion of patients in all the filgotinib treatment groups (50 mg, 67\% (48/72); $100 \mathrm{mg}, 66 \%(46 /$ $70) ; 200 \mathrm{mg}, 73 \%(50 / 69)$ ) achieved an ACR20 response compared with placebo $(29 \%(21 / 72))$ (all $\mathrm{p}<0.0001$; figure $2 \mathrm{~A})$. Raw ACR20 data for each time point are presented in online supplementary table S1.

\section{Secondary efficacy analyses}

At week 12, a statistically significantly greater proportion of patients had an ACR50 response in all filgotinib dose groups compared with placebo $(\mathrm{p}<0.05$; figure $2 \mathrm{~B})$. In the 100 and $200 \mathrm{mg}$ groups, patients were more likely to achieve ACR70 compared with placebo (figure 2C). These responses persisted (ACR50) or even improved (ACR70) up to week 24. The ACR20 response appeared to plateau around week 8 and was maintained throughout the rest of the study to week 24 (figure 2A).

An early onset of response was observed for ACR20 (statistically significantly higher at week 1 in the filgotinib $200 \mathrm{mg}$ group figure 2A), ACR50 (from week 2 in the filgotinib $200 \mathrm{mg}$ oncedaily dose group) and ACR70 (week 4 in the filgotinib $200 \mathrm{mg}$ once-daily dose group). Patients randomised to placebo and those on filgotinib $50 \mathrm{mg}$ who were considered non-responders and were switched to filgotinib $100 \mathrm{mg}$ at week 12 showed increased ACR20/50/70 responses at week 24, similar to the week 12 responses seen in patients randomised to receive filgotinib $100 \mathrm{mg}$ from baseline (see online supplementary figure S1).

At week 12, there was a significantly greater mean decrease in DAS28 (CRP) for all filgotinib groups, compared with placebo, which was maintained in the $50 \mathrm{mg}$ dose group and showed a small improvement in the higher dose groups at week 24 (figure 2D). These improvements in DAS28 (CRP) versus placebo were evident at week 1 in all filgotinib groups. A similar pattern in terms of disease activity was observed for CDAI (figure 2E). Improvements in HRQoL were noted as early as week 2 for the filgotinib $200 \mathrm{mg}$ group; by week 12, significant improvements from baseline were noted in all active treatment groups (figure $2 \mathrm{~F}$ ). Raw data for each of the secondary efficacy end points illustrated in figure 2 are presented in online supplementary table S1.

There were trends in favour of the active treatment across various definitions of disease remission and responses to treatment; statistical significance versus placebo was observed at week 12 for all filgotinib dose groups for ACR-N, DAS28 (CRP) EULAR 'good' responses and SDAI (table 2). Higher doses of filgotinib were generally associated with the most substantial reductions in disease activity and the highest disease remission rates (table 2).

There were too few patients in each dose group who had previously received and responded to a biological agent to make valid comparisons of the efficacy of filgotinib in this patient population, versus patients who were naïve to biological treatments.

\section{Safety}

Adverse events

Treatment-emergent AEs (TEAEs) were reported at similar frequencies across all groups from baseline to week 12 (the period during which placebo could be compared directly with active treatment) and to week 24 (table 3). Of nine serious TEAEs occurring up to week 24, there were four serious infections. Overall, three serious TEAEs occurred in the filgotinib $200 \mathrm{mg}$ group (back pain, osteoarthritis, pneumonia), two occurred in the filgotinib $100 \mathrm{mg}$ group (cellulitis, vertigo), two in the filgotinib $50 \mathrm{mg}$ group (gastroenteritis, humerus fracture) and two in the placebo group (RA worsening (prior to switching treatment), and chronic pyelonephritis) (table 3 ). A greater proportion of TEAEs were considered related to study treatment in the 
Table 1 Baseline patient demographics, disease characteristics and treatment history

\begin{tabular}{|c|c|c|c|c|}
\hline \multirow{3}{*}{ Patient demographics } & \multirow[b]{2}{*}{$\begin{array}{l}\text { Placebo } \\
\mathrm{N}=72\end{array}$} & \multicolumn{3}{|c|}{ Filgotinib once daily } \\
\hline & & \multirow[t]{2}{*}{$\begin{array}{l}50 \mathrm{mg} \\
\mathrm{N}=72\end{array}$} & \multirow[t]{2}{*}{$\begin{array}{l}100 \mathrm{mg} \\
\mathrm{N}=70\end{array}$} & \multirow[t]{2}{*}{$\begin{array}{l}200 \mathrm{mg} \\
\mathrm{N}=69\end{array}$} \\
\hline & & & & \\
\hline Age, mean (SE), years & $52(1.4)$ & $52(1.6)$ & $53(1.4)$ & $52(1.4)$ \\
\hline Female, n (\%) & $56(77.8)$ & $62(86.1)$ & $53(75.7)$ & $60(87.0)$ \\
\hline \multicolumn{5}{|l|}{ Disease characteristics } \\
\hline Duration of $R A$, mean (SE), years & $10(0.8)$ & $9(0.8)$ & $9(0.8)$ & $9(1.0)$ \\
\hline Anti-CCP positive, n (\%) & $58(80.6)$ & $56(77.8)$ & $54(77.1)$ & $57(82.6)$ \\
\hline RF positive, $\mathrm{n}(\%)$ & $57(79.2)$ & $53(73.6)$ & $51(72.9)$ & $50(72.5)$ \\
\hline DAS28 (CRP), mean (SE) & $6.22(0.099)$ & $6.03(0.105)$ & $6.18(0.101)$ & $6.09(0.102)$ \\
\hline CDAl, mean (SE) & $42(1.3)$ & $41(1.5)$ & $44(1.5)$ & $42(1.4)$ \\
\hline SDAl, mean (SE) & $46(1.5)$ & $44(1.6)$ & $47(1.7)$ & $44(1.5)$ \\
\hline \multicolumn{5}{|l|}{ ACR components } \\
\hline CRP, mean (SE), mg/L & $35.26(4.434)$ & $24.67(3.257)$ & $25.55(4.247)$ & $23.16(2.492)$ \\
\hline TJC68, mean (SE) & $25.23(1.480)$ & $25.58(1.620)$ & $27.20(1.770)$ & $26.24(1.506)$ \\
\hline TJC28, mean (SE) & $15.85(0.715)$ & $15.30(0.790)$ & $16.52(0.820)$ & $16.58(0.750)$ \\
\hline SJC66, mean (SE) & $15.98(0.853)$ & $16.97(1.074)$ & $18.65(1.418)$ & $15.74(1.047)$ \\
\hline SJC28, mean (SE) & $12.18(0.596)$ & $12.55(0.710)$ & $13.19(0.760)$ & $11.58(0.654)$ \\
\hline HAQ-DI total score, mean & $1.80(0.058)$ & $1.84(0.068)$ & $1.81(0.068)$ & $1.80(0.063)$ \\
\hline Patient's global assessment, mean (SE) & $71.1(2.02)$ & $68.6(2.41)$ & $71.5(2.23)$ & $68.9(2.07)$ \\
\hline Investigator's global assessment, mean (SE) & $70.4(1.73)$ & $68.2(1.73)$ & $72.0(1.59)$ & $67.7(1.86)$ \\
\hline Patient's pain, mean (SE) & $71.6(2.37)$ & $71.0(2.38)$ & $72.6(1.85)$ & $68.1(2.35)$ \\
\hline \multicolumn{5}{|l|}{ Treatments } \\
\hline Corticosteroids, n (\%) & $45(62.5)$ & $47(65.3)$ & $50(71.4)$ & $47(68.1)$ \\
\hline Duration of corticosteroid use, mean (SE), years & $4.59(0.791)$ & $5.31(0.771)$ & $3.39(0.528)$ & $5.41(0.757)$ \\
\hline Previous biological DMARD use, $\mathrm{n}(\%)$ & $3(4.2)$ & $7(9.7)$ & $4(5.7)$ & $5(7.2)$ \\
\hline Previous conventional DMARD use ${ }^{*}, \mathrm{n}(\%)$ & $71(98.6)$ & 70 (97.2) & $68(97.1)$ & $67(97.1)$ \\
\hline MTX, n (\%) & $60(83.3)$ & $61(84.7)$ & $59(84.3)$ & $58(84.1)$ \\
\hline MTX-sodium, n (\%) & $5(6.9)$ & $4(5.6)$ & $7(10.0)$ & $6(8.7)$ \\
\hline Duration of prior MTX use, mean (SE), years & $4.86(0.656)$ & $4.44(0.557)$ & $3.55(0.464)$ & $3.85(0.435)$ \\
\hline
\end{tabular}

*Patients had MTX washed out for $\geq 4$ weeks before or during screening.

ACR, American College of Rheumatology; CCP, cyclic citrullinated peptide; CDAl, Clinical Disease Activity Index; CRP, C reactive protein; DAS28, Disease Activity Score based on 28 joints; DMARD, disease-modifying antirheumatic drug; HAQ-DI, Health Assessment Questionnaire-Disability Index; MTX, methotrexate; N, number of patients per treatment group; $n$, number of patients per category; RA, rheumatoid arthritis; RF, rheumatoid factor; SDAl, Simple Disease Activity Index; SJC28, swollen joint count based on 28 joints; SJC66, swollen joint count based on 66 joints; TJC28, tender joint count based on 28 joints; TCJ68, tender joint count based on 68 joints.

filgotinib groups compared with placebo (table 3). Occurrences of TEAEs leading to discontinuation were similarly rare in all treatment groups, with a greater proportion of TEAEs leading to discontinuations in the placebo group (table 3). There was one case of herpes zoster during the study, which occurred during weeks $12-24$ of the study in a patient receiving filgotinib $50 \mathrm{mg}$ once daily; the infection resolved after 10 days. No cases of $\mathrm{TB}$, opportunistic infections, lymphoma or cancer were reported throughout the 24 -week treatment period.

\section{Haematology}

Up to week 12, increases in mean haemoglobin concentrations were observed in the filgotinib 100 and $200 \mathrm{mg}$ groups (up to $0.39 \mathrm{~g} / \mathrm{dL}$, a $3.4 \%$ increase in the $200 \mathrm{mg}$ group). These remained stable to week 24 . In patients who were switched to filgotinib $100 \mathrm{mg}$ at week 12, there were increases in mean haemoglobin concentration between weeks 12 and 24 (table 4, see online supplementary figure S2). Decreases in mean neutrophil counts were seen in filgotinib groups through to week 4 that appeared to plateau thereafter and remained stable until week 24, with the exception of an overall decrease to week 24 in patients who were switched from filgotinib 50 to $100 \mathrm{mg}$ (see online supplementary figure S2). Two patients experienced CTCAE grade 3 abnormally low neutrophil counts during filgotinib treatment (neither with concomitant infections); both continued their filgotinib treatment. Overall, more increases than decreases were observed in mean absolute lymphocyte counts, and there were no apparent correlations between treatment groups and mean lymphocyte counts over time (table 4). There were no decreases from baseline in lymphocyte subsets, including mean natural killer (NK) cell counts. Three patients on filgotinib treatment experienced CTCAE grade 3 abnormally low lymphocyte counts (table 3 ). One patient had an abnormally low lymphocyte count at baseline and the other two had a coinciding mild infection (urinary tract and pharyngitis). Five patients discontinued the study due to lymphopenia (two subjects receiving placebo and three subjects receiving filgotinib), as per protocol stopping rule of precautionary discontinuation for two sequential lymphocyte counts $<0.75 \times 10^{9}$ cells/L. Absolute platelet counts decreased in all filgotinib groups by week 4 , but thereafter the counts remained stable up to week 24 (decreases from baseline of 44.7 and $22.3 \times 10^{9} / \mathrm{L}$, respectively, in the filgotinib 100 and $200 \mathrm{mg}$ groups) (table 4). 

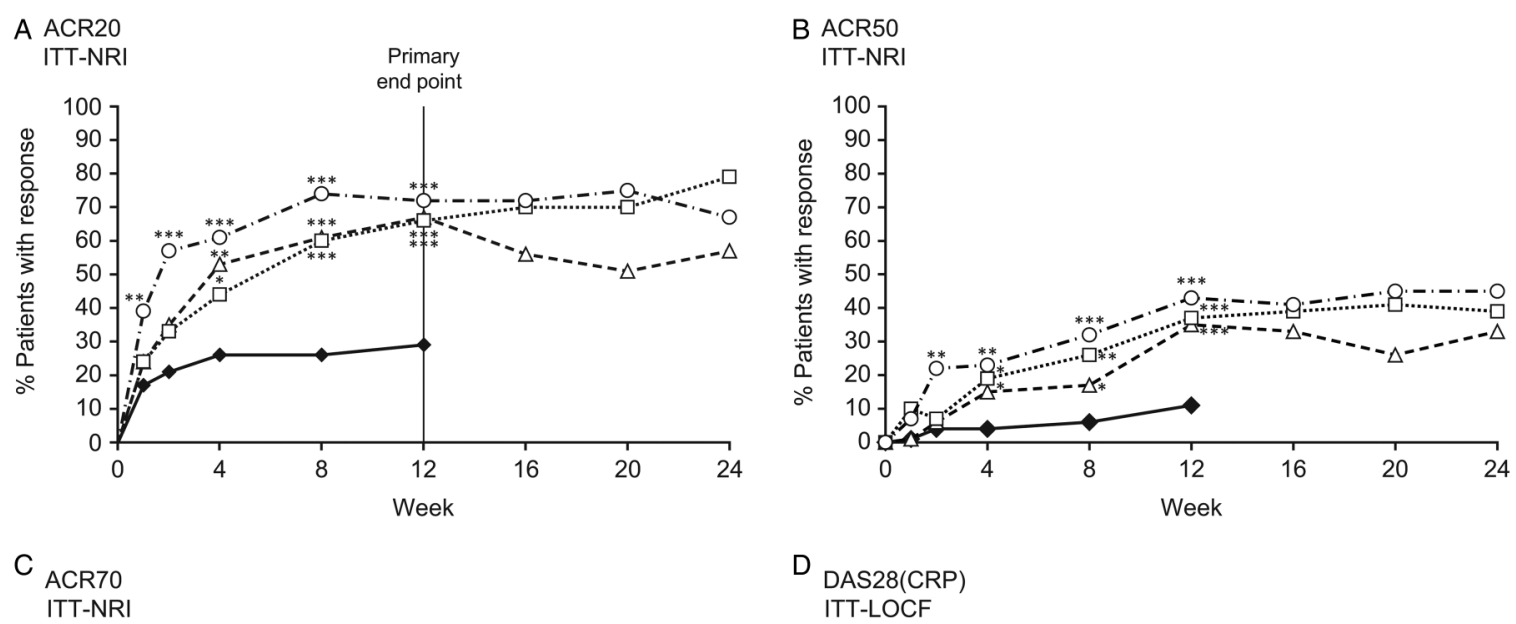

D DAS28(CRP)
ITT-LOCF
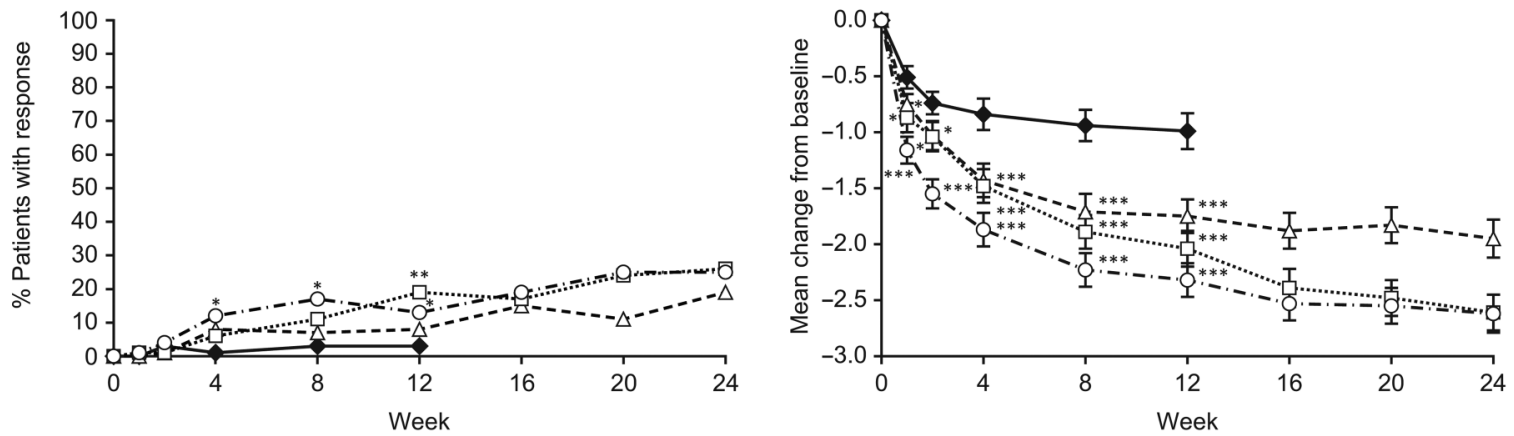

E CDAI ITT-LOCF

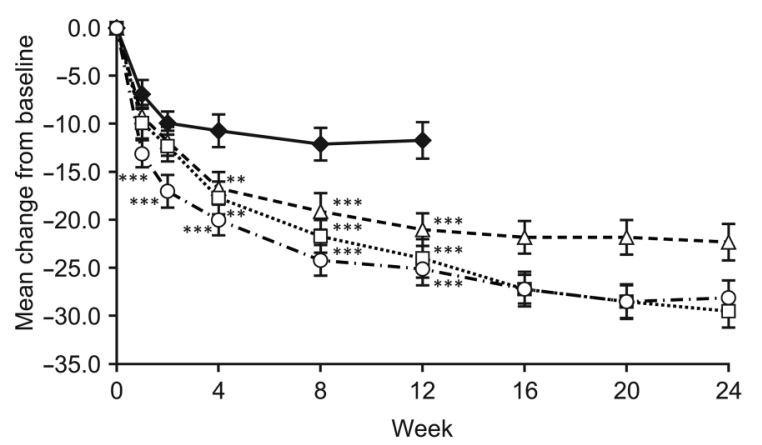

$F_{\text {HAQ-DI }}$

ITT-LOCF

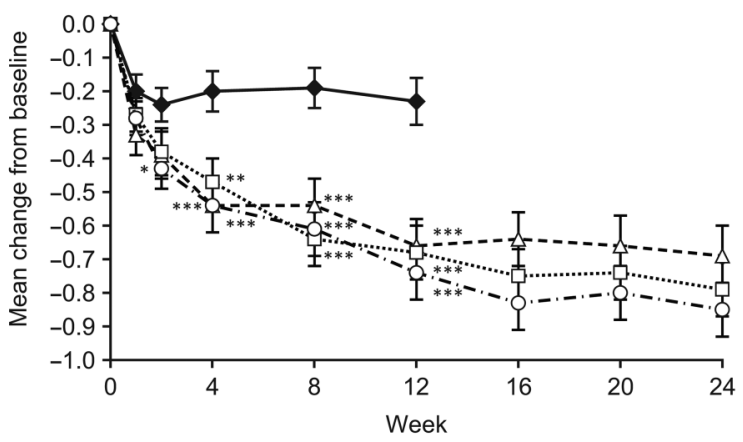

$-\triangleleft \cdot 50 \mathrm{mg} \quad \cdots \cdot \square \cdot \cdots \cdot 100 \mathrm{mg} \quad-\cdot 0 \cdot-200 \mathrm{mg} \quad \longrightarrow$ Placebo

Figure 2 Efficacy end points. The percentage of patients achieving an improvement in American College of Rheumatology (ACR) of (A) 20\% (ACR20); (B) 50\% (ACR50); (C) 70\% (ACR70) over time though 24 weeks; (D) mean change from baseline in DAS28 (CRP) over time; (E) mean change from baseline CDAl over time; (F) mean change from baseline in HAQ-DI over time. The vertical line at 12 weeks in $2 \mathrm{~A}$ indicates the primary efficacy time point (NRI (ITT population)). Patients who switched treatment at week 12 are treated as if they discontinued treatment at week 12. ${ }^{*} p<0.05 ;{ }^{*} p<0.01 ;{ }^{* *} p<0.001$. CDAl, Clinical Disease Activity Index; CRP, C reactive protein; DAS, Disease Activity Score; HAQ-DI, Health Assessment Questionnaire-Disability Index; ITT, intent-to-treat; LOCF, last observation carried forward; NRI, non-responder imputation.

Clinical chemistry

Up to week 4, dose-dependent increases were observed in mean creatinine concentrations with filgotinib (see online supplementary figure S2); these subsequently plateaued in the filgotinib 100 and $200 \mathrm{mg}$ groups and remained stable until week 24 , with overall increases of up to $3.5 \mu \mathrm{mol} / \mathrm{L}$ in the filgotinib $200 \mathrm{mg}$ group. Mean lipase concentrations remained stable throughout the study in all treatment groups, although for the filgotinib $200 \mathrm{mg}$ group a small increase from baseline was observed in mean concentrations at all time points (increase of $2.9 \mathrm{U} / \mathrm{L}$ from $26.4 \mathrm{U} / \mathrm{L}$ at baseline in the filgotinib $200 \mathrm{mg}$ oncedaily group as of week 24). Mean alanine transaminase (ALT) and aspartate transaminase (AST) concentrations remained stable throughout the study in all treatment groups (table 4) with the exception of two high values (one in the continued filgotinib $100 \mathrm{mg}$ group and one in the group switching from placebo to filgotinib $100 \mathrm{mg}$ ) (data not shown). One patient in the filgotinib $200 \mathrm{mg}$ group had a CTCAE grade 3 abnormally high total cholesterol value. One patient had CTCAE grade 3 increases in both ALT and AST, one patient had a CTCAE grade 3 increase in AST (table 3); no patients discontinued their study treatment because of ALT or AST elevations. Mean levels of total cholesterol, high-density lipoprotein (HDL) and lowdensity lipoprotein (LDL) cholesterol increased in the filgotinib 
Table 2 Efficacy assessments at weeks 12 and 24 (NRI (ITT population) and LOCF (ITT population))

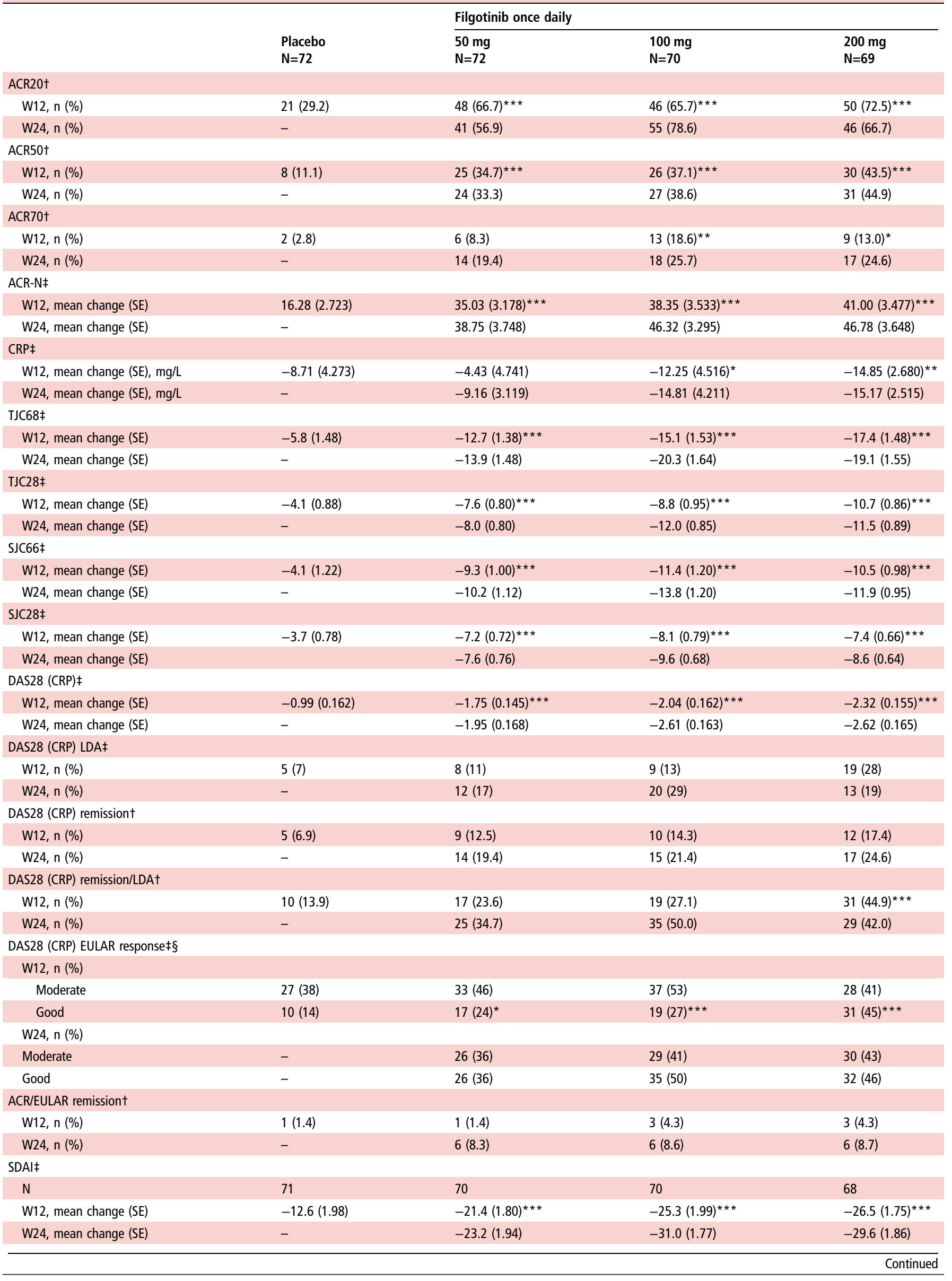




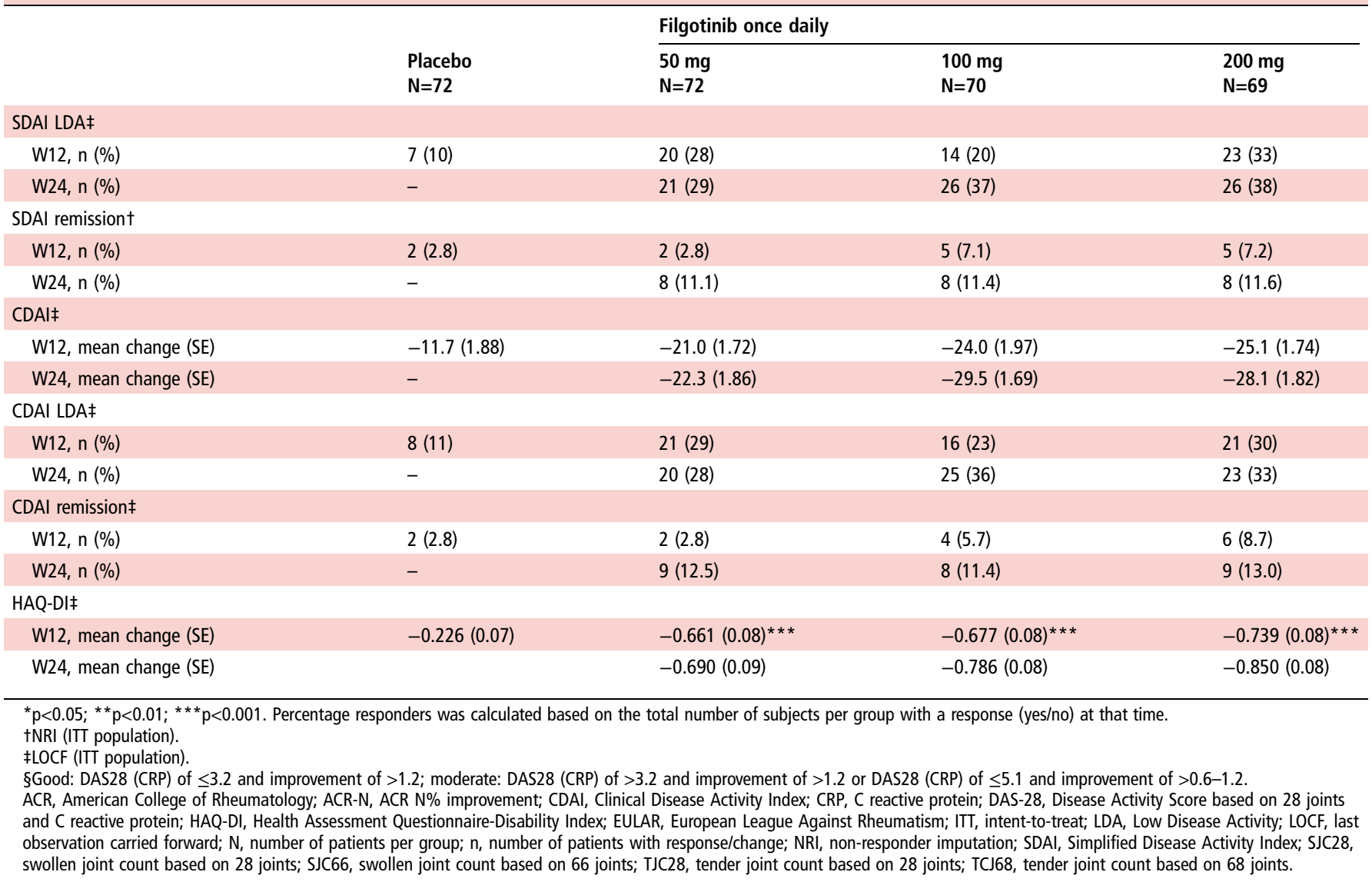

100 and $200 \mathrm{mg}$ groups up to week 4, but plateaued and remained stable to week 24 (see online supplementary figure S2). The LDL:HDL ratio fell slightly over the study period indicating that proportional increases in HDL cholesterol were greater than those in LDL cholesterol. There were increases in mean triglycerides in filgotinib groups with no apparent dose relationship (data not shown).

\section{DISCUSSION}

In this study, clinical efficacy in patients treated with filgotinib monotherapy provided statistically significant, dose-dependent improvements in the signs and symptoms of active RA, and clinical improvements were evident soon after active treatment had begun. Clinical improvements were paralleled by rapid improvements in HRQoL.

Consistent with previous studies, ${ }^{13}$ filgotinib was well tolerated at all the doses evaluated, with similar proportions of patients experiencing TEAEs in the placebo and filgotinib treatment groups. Serious AEs and those leading to study discontinuation were relatively low: of the 283 patients treated overall in this study, 9 had a serious TEAE (8 receiving filgotinib) and 11 subjects had $\geq 1$ TEAE leading to permanent study discontinuation. There were four serious infections occurring in subjects receiving filgotinib and this risk warrants further evaluation in future clinical trials. Increases in mean haemoglobin were observed in filgotinib treatment groups, along with reductions in neutrophils, but these were mostly considered by investigators as without clinical consequence and did not lead to study discontinuation. In agreement with the short-term phase IIa studies of filgotinib, no reduction in lymphocyte or NK cell counts was observed ${ }^{8}$ and a small decline in platelet counts plateaued at week 4 but remained stable thereafter. Although small (up to $3.5 \mu \mathrm{mol} / \mathrm{L}$ in the highest dose group) increases in creatinine were observed with filgotinib, effects on the liver were minimal. AST and ALT levels were stable throughout the study. In line with other studies, increases in both HDL and LDL cholesterol were seen with filgotinib treatment, however, the LDL:HDL ratio fell during the study, thereby indicating greater increases in HDL compared with LDL. Throughout the study, CTCAE grade 3 or 4 laboratory abnormalities were infrequent (11 events reported overall), and in most cases did not lead to study discontinuation.

Among the limitations of the study, the duration of the placebo control period was only 12 weeks because of the ethical implications inherent in continuing patients with active RA on placebo for a longer duration. As the therapeutic options of RA continue to evolve, from an ethical perspective, future studies would ideally use an active comparator instead of placebo to evaluate the efficacy and safety of novel compounds, such that no patient with moderately to severely active RA is left without potentially efficacious medication. Although the placebo period ended at 12 weeks, the study remained double blind to dose through to 24 weeks. The relatively short ( 24 weeks) duration of the study also limits interpretation of side effects. Radiographic assessments were not included in the study design, so the impact of filgotinib on the physical structure of bones and joints could not be evaluated. In conclusion, the results of this phase IIb study of filgotinib without background MTX treatment demonstrate improvements in the signs and symptoms of active RA, with an early onset, sustained effect and an acceptable safety 


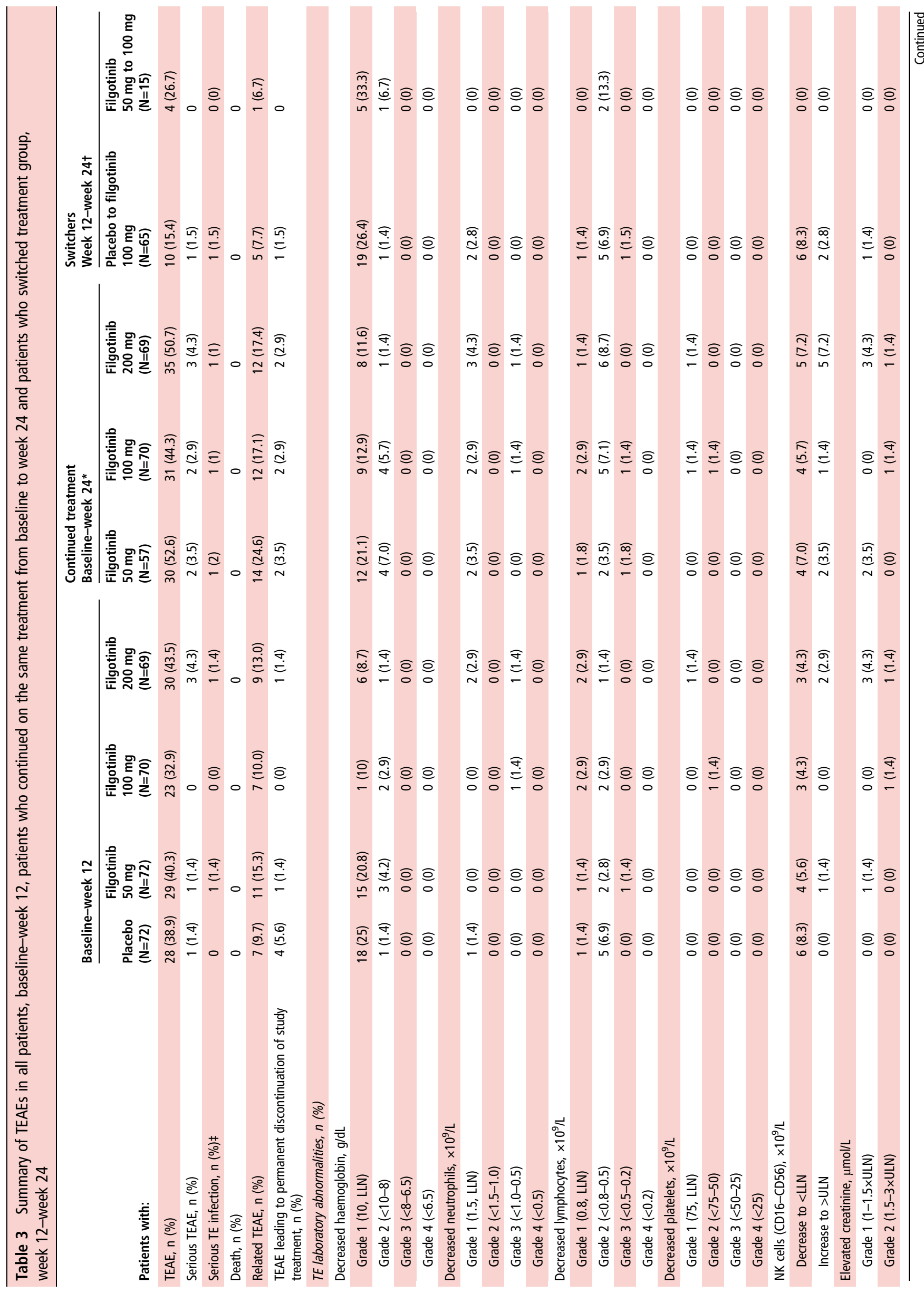




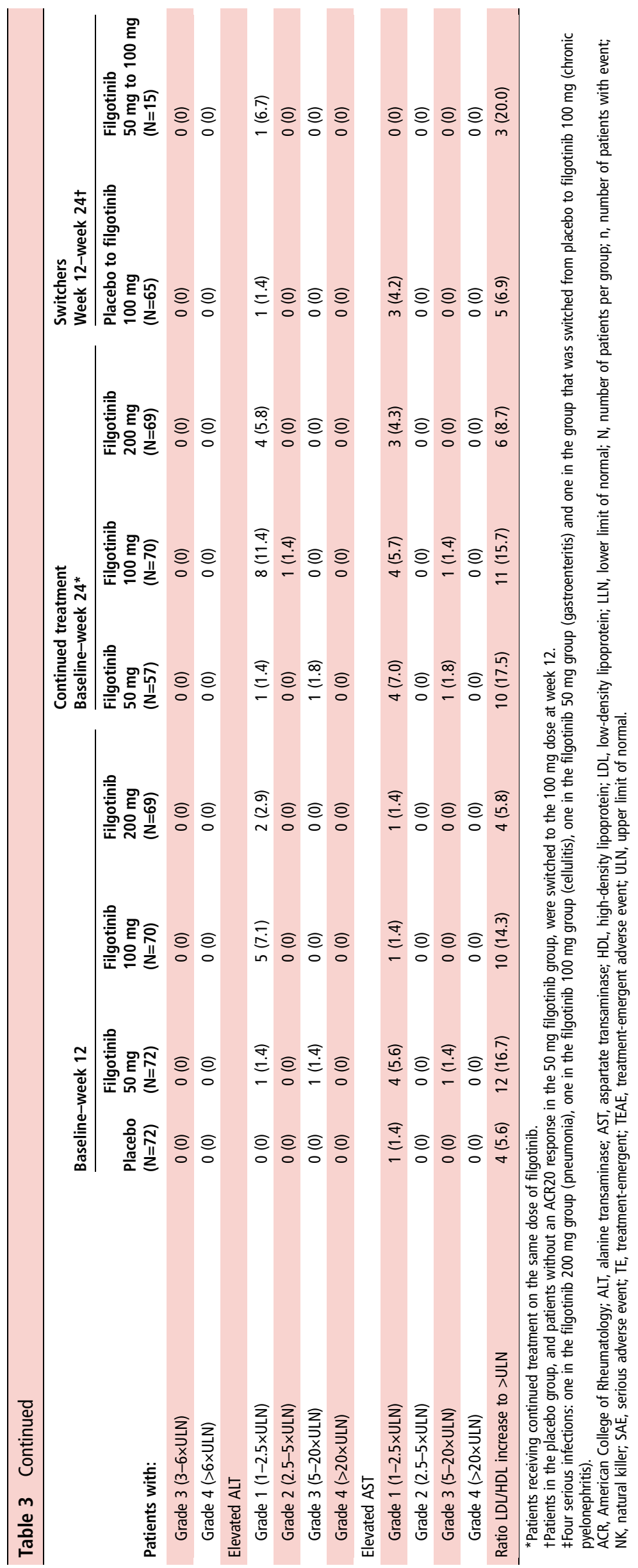


Table 4 Summary of laboratory data at weeks 12 and 24 (data represented are mean change from baseline \pm SE)

\begin{tabular}{|c|c|c|c|c|c|}
\hline \multirow[b]{2}{*}{ Haemoglobin, $\mathrm{g} / \mathrm{dL}$} & \multirow[b]{2}{*}{$\begin{array}{l}\text { Placebo to filgotinib } \\
100 \mathrm{mg} \\
\mathrm{N}=72\end{array}$} & \multicolumn{4}{|c|}{ Filgotinib once daily } \\
\hline & & $\begin{array}{l}50 \mathrm{mg} \text { continued } \\
\mathrm{N}=57\end{array}$ & $\begin{array}{l}50 \mathrm{mg} \text { switching } \\
\text { to } 100 \mathrm{mg} \\
\mathrm{N}=15\end{array}$ & $\begin{array}{l}100 \mathrm{mg} \text { continued } \\
\mathrm{N}=70\end{array}$ & $\begin{array}{l}200 \mathrm{mg} \text { continued } \\
\mathrm{N}=69\end{array}$ \\
\hline W12 & $0.02(0.11)$ & $0.26(0.11)$ & $-0.18(0.12)$ & $0.31(0.12)$ & $0.39(0.11)$ \\
\hline W24 & $0.34(0.12)$ & $0.20(0.16)$ & $0.69(0.30)$ & $0.28(0.13)$ & $0.24(0.11)$ \\
\hline \multicolumn{6}{|l|}{ Lymphocytes, $\times 10^{9} / \mathrm{L}$} \\
\hline W12 & $0.20(0.10)$ & $-0.11(0.10)$ & $0.17(0.17)$ & $0.21(0.10)$ & $0.03(0.11)$ \\
\hline W24 & $0.10(0.09)$ & $-0.10(0.14)$ & $0.36(0.13)$ & $0.10(0.10)$ & $0.09(0.12)$ \\
\hline \multicolumn{6}{|l|}{ Neutrophils, $\times 10^{9} / \mathrm{L}$} \\
\hline W12 & $-0.22(0.28)$ & $-0.16(0.42)$ & $-0.87(0.71)$ & $-1.22(0.30)$ & $-1.25(0.29)$ \\
\hline W24 & $-0.66(0.33)$ & $-0.56(0.44)$ & $-2.34(0.48)$ & $-1.04(0.32)$ & $-1.43(0.30)$ \\
\hline \multicolumn{6}{|l|}{ Platelets, $\times 10^{9} / \mathrm{L}$} \\
\hline W12 & $8.2(6.7)$ & $-10.3(10.0)$ & $-14.3(11.2)$ & $-30.4(7.3)$ & $-27.9(8.4)$ \\
\hline W24 & $-31.8(6.8)$ & $-26.1(9.6)$ & $-28.6(10.5)$ & $-44.7(7.9)$ & $-22.3(7.7)$ \\
\hline \multicolumn{6}{|l|}{ Creatinine, $\mu \mathrm{mol} / \mathrm{L}$} \\
\hline W12 & $0.16(0.95)$ & $4.04(1.42)$ & $0.02(1.57)$ & $1.8(1.10)$ & $3.8(1.10)$ \\
\hline W24 & $4.57(1.16)$ & $1.61(1.09)$ & $5.24(1.78)$ & $1.97(1.14)$ & $3.49(1.21)$ \\
\hline \multicolumn{6}{|l|}{ ALT, U/L } \\
\hline W12 & $-0.8(0.91)$ & $-1.6(1.18)$ & $-0.9(1.05)$ & $1.3(1.48)$ & $-1.1(1.43)$ \\
\hline W24 & $0.9(1.05)$ & $-0.2(1.89)$ & $3.2(2.33)$ & $0.4(1.74)$ & $-1.3(1.59)$ \\
\hline \multicolumn{6}{|l|}{ AST, U/L } \\
\hline W12 & $-0.70(0.73)$ & $-0.5(0.93)$ & $0.8(1.00)$ & $1.9(0.97)$ & $1.1(1.05)$ \\
\hline W24 & $2.1(0.86)$ & $-0.5(1.19)$ & $2.6(1.72)$ & $1.5(1.00)$ & $1.4(1.29)$ \\
\hline \multicolumn{6}{|c|}{ LDL cholesterol, mmol/L } \\
\hline W12 & $-0.01(0.06)$ & $0.09(0.09)$ & $0.11(0.13)$ & $0.28(0.10)$ & $0.35(0.07)$ \\
\hline W24 & $0.10(0.07)$ & $0.00(0.11)$ & $0.14(0.17)$ & $0.31(0.10)$ & $0.38(0.07)$ \\
\hline \multicolumn{6}{|c|}{ HDL cholesterol, mmol/L } \\
\hline W12 & $0.03(0.04)$ & $0.06(0.04)$ & $0.150(0.06)$ & $0.19(0.03)$ & $0.19(0.04)$ \\
\hline W24 & $0.16(0.04)$ & $0.17(0.05)$ & $0.30(0.07)$ & $0.18(0.03)$ & $0.19(0.04)$ \\
\hline
\end{tabular}

ALT, alanine transaminase; AST, aspartate transaminase; HDL, high-density lipoprotein; LDL, low-density lipoprotein; N, number of patients per group.

profile. These encouraging data support the future development of filgotinib monotherapy for treatment of patients who have had an inadequate response to MTX treatment.

\author{
Author affiliations \\ ${ }^{1}$ University of California San Diego, San Diego, California, USA \\ ${ }^{2}$ Center for Rheumatology, Albany Medical College, Albany, New York, USA \\ ${ }^{3}$ Consulta Privada Dra. Lucia Ponce, Temuco, Chile \\ ${ }^{4}$ Revita Reumatologiai Rendelo, Budapest, Hungary \\ ${ }^{5}$ Regional Clinical Hospital, Saratov, Russia \\ ${ }^{6}$ Vinnitsa Regional Clinical Hospital, Pirogov, Ukraine \\ ${ }^{7}$ Desert Medical Advances, Palm Desert, California, USA \\ ${ }^{8}$ Galapagos NV, Mechelen, Belgium
}

Acknowledgements The authors would like to thank the members of the DARWIN 2 study group, the Contract Research Organisation involved and all patients who participated in the trial.

Contributors AK, JK, AVdA, FV, CT and PH contributed to conception, collation and analysis of data. All authors contributed to the writing of the paper and participated in the review and interpretation of the data. All authors read and approved the final manuscript.

Funding The work presented here, including the conduct of the study, data analysis and interpretation, was supported by Galapagos NV. Editorial assistance in the preparation of the manuscript was provided by Fishawack Communications, which was funded by Galapagos NV.

Competing interests AK has received compensation for consultancy work, or has been involved in the conduct of clinical research studies, for AbbVie, Amgen, Celgene, Eli Lilly, Janssen, Novartis, Pfizer and UCB, and has consulted for Galapagos NV. JK has received compensation for consultancy work from AbbVie, BMS, Genentech, Lilly, Novartis and Pfizer, and has received grant support from
AbbVie, Genentech, Eli Lilly, Novartis and Pfizer; he is an employee of The Consortium of Rheumatology Researchers of North America. LP has received honoraria from Bristol-Myers Squibb and Pfizer. MG has been involved in clinical research studies for AbbVie, Amgen, Astellas, Celgene, Eli Lilly, Galapagos, Merck, Pfizer and UCB. RC, OVR and MS were DARWIN 2 study investigators, funded by Galapagos NV. AVdA, FV, CT and PH are employees of Galapagos NV.

Ethics approval The relevant Ethics Committee/Institutional Review Board approval was obtained at each study site.

Provenance and peer review Not commissioned; externally peer reviewed.

Open Access This is an Open Access article distributed in accordance with the Creative Commons Attribution Non Commercial (CC BY-NC 4.0) license, which permits others to distribute, remix, adapt, build upon this work non-commercially, and license their derivative works on different terms, provided the original work is properly cited and the use is non-commercial. See: http://creativecommons.org/ licenses/by-nc/4.0/

\section{REFERENCES}

1 Jeurissen ME, Boerbooms AM, van de Putte LB, et al. Influence of methotrexate and azathioprine on radiologic progression in rheumatoid arthritis. A randomized, double-blind study. Ann Intern Med 1991;114:999-1004.

2 Hazlewood GS, Barnabe C, Tomlinson G, et al. Methotrexate monotherapy and methotrexate combination therapy with traditional and biologic disease modifying antirheumatic drugs for rheumatoid arthritis: abridged Cochrane systematic review and network meta-analysis. BMJ 2016;353:i1777.

3 Müller RB, von Kempis J, Haile SR, et al. Effectiveness, tolerability, and safety of subcutaneous methotrexate in early rheumatoid arthritis: a retrospective analysis of real-world data from the St. Gallen cohort. Semin Arthritis Rheum 2015;45:28-34

4 Schwartz DM, Bonelli M, Gadina M, et al. Type I/II cytokines, JAKs, and new strategies for treating autoimmune diseases. Nat Rev Rheumatol 2016;12:25-36. 
5 Pfizer Inc. Xeljanz® (tofacitinib) prescribing information. Last revised Nov 2012.

6 Norman P. Selective JAK inhibitors in development for rheumatoid arthritis. Expert Opin Investig Drugs 2014;23:1067-77.

7 Namour F, Desrivot J, Van der Aa A, et al. Clinical confirmation that the selective JAK1 inhibitor filgotinib (GLPG0634) has a low liability for drug-drug interactions. Drug Metab Lett 2016;10:38-48.

8 Galien R, Brys R, Van der Aa A, et al. Absence of effects of filgotinib on erythrocytes, CD8+ and NK cells in rheumatoid arthritis patients brings further evidence for the JAK1 selectivity of filgotinib. [abstract] Arthritis Rheumatol 2015;67 (Suppl 10):2781.

9 Van Rompaey L, Galien R, van der Aar EM, et al. Preclinical characterization of GLPG0634, a selective inhibitor of JAK1, for the treatment of inflammatory diseases. J Immunol 2013;191:3568-77.
10 Namour F, Diderichsen PM, Cox E, et al. Pharmacokinetics and pharmacokinetic pharmacodynamic modeling of filgotinib (GLPG0634), a selective JAK1 inhibitor, in support of phase IIB dose selection. Clin Pharmacokinet 2015;54:859-74.

11 Vanhoutte F, Mazur M. Efficacy and safety of GLPG0634, a selective JAK1 inhibitor, after short-term treatment of rheumatoid arthritis; results of a phase IIA trial. Ann Rheum Dis 2012;71(Suppl 3):145.

12 Ongenaert M, Dupont S, Vayssière B, et al. Treatment of rheumatoid arthritis patients with the JAK1-selective inhibitor GLPG0634 reverses an arthritis-specific blood gene signature to healthy state. [abstract] Arthritis Rheumatol 2015;66(Suppl 10):1494.

13 Tasset C, Harrison P, van der Aa A, et al. The JAK1-selective inhibitor GLPG0634 is safe and rapidly reduces disease activity in patients with moderate to severe rheumatoid arthritis; results of a 4-week dose ranging study. [abstract] Arthritis Rheumatol 2013;65(Suppl 10):2381. 